\title{
Tumor necrosis factor $\alpha$-induced protein 3 (A20) is dysregulated in pediatric Crohn disease
}

This article was published in the following Dove Press journal: Clinical and Experimental Gastroenterology

\author{
Deenaz Zaidi',2 \\ Hien Q Huynh' \\ Matthew W Carroll' \\ Shairaz Baksh 1,3,4 \\ Eytan Wine 1,2,5 $^{1,3,4}$ \\ 'Department of Pediatrics, \\ ${ }^{2}$ Department of Medicine, Centre \\ of Excellence for Gastrointestinal \\ Inflammation and Immunity \\ Research (CEGIIR), ${ }^{3}$ Department of \\ Biochemistry, ${ }^{4}$ Department of \\ Oncology, Cancer Institute \\ of Northern Alberta (CRINA), \\ ${ }^{5}$ Department of Physiology, University \\ of Alberta, Edmonton, AB, Canada
}

Correspondence: Eytan Wine Division of Pediatric Gastroenterology and Nutrition, Department of Pediatrics, University of Alberta, Edmonton Clinic Health Academy, Room 4-577, I I 405

87th Avenue, Edmonton, AB T6G IC9 Canada

Tel +I 7802485420

Fax + I 888353 II 57

Email wine@ualberta.ca
Purpose: A significant feature of pediatric inflammatory bowel diseases (IBD), which include Crohn disease (CD), and ulcerative colitis (UC), is failure to suppress inflammation. The inability to regulate inflammation renders a major challenge toward establishing effective treatments in IBD. Nuclear factor kappa-light-chain-enhancer of activated B-cells-induced inflammation is inhibited by A20 through interactions with TAX1BP1 (Tax1-binding protein 1) and A20-binding inhibitor of NF- $\kappa \beta$ activation (ABIN)-1 (A20 binding and inhibitor of NF- $\kappa \beta$ ) and upon phosphorylation by inhibitor of nuclear factor kappa- $\beta$ kinase subunit beta (IKK $\beta)$, which stabilizes it. We hypothesized that dysregulation of A20 is an important factor in uncontrolled inflammation in pediatric IBD.

Patients and methods: Gene expression of $A 20, I K K \beta, A B I N-1, T A X 1 B P 1$, A20 protein, cytokine levels, and A20 phosphorylation was analyzed in the terminal ileum (TI) of 39 patients ( 14 non-IBD, 15 CD, and $10 \mathrm{UC}$ ). A20 expression and protein in T-84 cells and ex vivo biopsies of patients were measured after treatment with Escherichia coli strains or tumor necrosis factor (TNF)- $\alpha$.

Results: TNF- $\alpha$ levels and $A 20$ expression were increased in the TI of CD patients. A20 protein levels and $A B I N-1$ expression were low, TAXIBPI expression was high, and $I K K \beta$ was unchanged. $A 20$ expression positively correlated with biopsy TNF- $\alpha$ levels and inflammatory markers in CD patients. A20 phosphorylation appeared lower in CD patients. $A 20$ expression in TI biopsies from CD patients and T84 cells was triggered with E. coli, strain LF82, while A20 protein levels remained unchanged.

Conclusion: We describe a potential mechanism related to failure of A20 to suppress inflammation in $\mathrm{CD}$, characterized by high $A 20$ expression and low A20 protein levels. The dysregulation of A20 is potentially due to alterations in $A B I N-1$, and infection with E. coli strain LF82 could affect the function and stability of A20. Our study signifies an important finding in A20 regulation in IBD, which prevents it from suppressing inflammation.

Keywords: A20, ABIN-1, inflammation, NF- $\kappa \beta$, TAX1BP1, E. coli

\section{Introduction}

Inflammatory bowel diseases (IBD), chiefly subcategorized into Crohn disease (CD) and ulcerative colitis (UC), are debilitating diseases of the gastrointestinal tract that frequently affect children and young adults. ${ }^{1,2}$ The etiology of IBD likely involves an uncontrolled immune response to environmental/microbial stimuli in genetically susceptible hosts.

Nuclear factor kappa-light-chain-enhancer of activated B-cells (NF- $\kappa \beta)$, a proinflammatory nuclear transcription factor, is a major player of immune-associated 
mechanisms. Overactivity of NF- $\kappa \beta$ and associated factors can lead to chronic inflammation and altered immunity, ${ }^{3,4}$ including in IBD. ${ }^{5}$ A20, also known as, tumor necrosis factor (TNF) $\alpha$-induced protein 3 (TNFAIP3), is a cytoplasmic inhibitor of $\mathrm{NF}-\kappa \beta$-induced inflammation and is triggered by lipopolysaccharide (LPS) and TNF- $\alpha$-induced NF- $\kappa \beta$ activation.

Genome-wide association studies have linked A20 with diseases, such as systemic lupus erythematous, IBD, and celiac disease, indicating that the role of A20 is "cell and disease-dependant". ${ }^{6}$ A20 has an important regulatory role in gut barrier protection during inflammation, as demonstrated by increased apoptosis and damaged intestinal epithelium after TNF- $\alpha$ treatment of intestinal epithelial cells-specific A20 knockout mice. ${ }^{7}$ TNF- $\alpha$ is associated with increased epithelial cell shedding and apoptosis in the gut, ${ }^{8}$ which definitely disrupts the gut barrier. Mice in which A20 was overexpressed in intestinal epithelial cells did not have increased intestinal permeability upon LPS administration, ${ }^{9}$ suggesting a possible protective role of A20 against bacteria.

Genetic variations in A20 are associated with IBD. ${ }^{6}$ Analysis of peripheral blood mononuclear cells showed decreased A20 mRNA expression in IBD patients than in non-IBD controls. ${ }^{10}$ In adult IBD patients, A20 profiling has shown variable correlation with disease phenotype and severity. A20 gene expression is low in the colonic and terminal ileum (TI) mucosa, ${ }^{11}$ and increased in colonic biopsies of adult UC, but, interestingly, not in CD patients. ${ }^{12}$

A20's anti-inflammatory effects are facilitated through interactions with other proteins, such as A20-binding inhibitor of NF- $\kappa \beta$ activation (ABIN)- $1^{13}$ and Tax 1-binding protein (TAX1BP)-1. ${ }^{14,15}$ ABIN-1 attaches A20 to the IKK/NEMO complex and assists it in exerting its deubiquitinating activity, which limits inflammation. ${ }^{13} A B I N-1$ expression depends on NF- $\kappa \beta$, and it also inhibits TNF- $\alpha$-mediated apoptosis. ${ }^{16}$ In mice, ABIN-1 was found to attach A20 to NEMO/IKK $\gamma$ and facilitate deubiquitination. ${ }^{13}$ TAX1BP1 inhibits NF- $\kappa \beta$ inflammation, ${ }^{14}$ and helps A20 regulate its deubiquitinating activities by recruiting A20 to the polyubiquitin chains to break and interrupt the IKK complex assembly. ${ }^{15}$ IKK $\beta$ phosphorylates A20 at the Serine 381 (S381) site, which stabilizes A20 and attenuates NF- $\beta$ signaling. ${ }^{17}$ Animal studies have reported that A20 in the phosphorylated state breaks Lys-63-linked polyubiquitin chains, which inhibits NF- $\kappa \beta$ signaling. ${ }^{18}$

Regulating or minimizing chronic inflammation is a major goal of IBD treatment, as most current treatments are immunosuppressant. Sustained inflammatory regulation is important for optimizing treatment and, hence, identification of novel factors (and characterizing mechanisms) that naturally regulate inflammation is critically needed in order to improve IBD management and to reduce the use of nonselective immunosuppressant medications. Given the fact that A20 can inhibit inflammation, and as TNF- $\alpha$-associated intestinal inflammation is a pivotal factor in IBD pathogenesis, we explored the correlation between TNF- $\alpha$ production, A20 expression, and disease status.

Prolonged disease course, comorbidities, and medication exposure robustly impact immunoregulatory pathways in adults and the ability to define their evolution. In contrast, investigating inflammatory paradigms in children, through unraveling the role of A20, could allow early insight into the gut inflammatory network, which can help toward an "immune-tailored" therapeutic approach.

We hypothesized that disruption in the regulation of A20, mediated by factors anchoring and stabilizing it, is an important contributory factor toward uncontrolled inflammation in IBD. In this study, we looked at the gene expression of $A 20, A B I N-1, I K K \beta, T A X 1 B P 1$, and A20 protein levels in TI biopsies of pediatric non-IBD and IBD patients. We also assessed the effects of Escherichia coli strains on A20 regulation in ex vivo TI biopsies of CD patients and T-84 cells.

We have shown, for the first time, a dysregulation in A20 in pediatric CD patients in the form of high $A 20$ gene expression and low A20 protein levels. The discrepancy in A20 gene and protein levels is possibly due to the concomitant lower expression of ABIN-1, offering a potential explanation for the failure of A20 to downregulate inflammation. An increase in A20 gene expression but not A20 protein as a result of treatment with $E$. coli strain LF82 suggests that microbes could limit the ability of A20 to suppress inflammation through mechanisms that are still unknown. Our study reports yet unexplored and novel findings in the setting of pediatric $\mathrm{CD}$, which could guide future studies to determine post-transcriptional modifications of A20 and its interaction with bacteria in inflammation in CD.

\section{Patients and methods}

\section{Patients}

The study included samples from a prospectively collected cohort of pediatric non-IBD and IBD patients undergoing gastroscopy and colonoscopy through the Edmonton Pediatric IBD Clinic (EPIC) in Canada. Prior to the study, ethics approval from the University of Alberta Research Ethics Board (Study ID Pro00023820) was obtained. All subjects had signed an informed consent to participate in the study. 
The control group included non-IBD patients undergoing endoscopy for intestinal symptoms, such as diarrhea and abdominal pain, but they were excluded upon any abnormal endoscopic or histologic mucosal finding. The IBD group included new and previously diagnosed CD and UC patients, based on the Porto criteria. ${ }^{19}$ Detailed clinical, laboratory, endoscopic, and histologic findings were prospectively recorded in the patient charts. All patients were given Pico$\operatorname{salax}^{\circledR}$ (sodium picosulfate with magnesium citrate) prior to the procedure for bowel preparation. After being administered general anesthesia with propofol and fentanyl by a pediatric anesthesiologist, endoscopies were performed by pediatric gastroenterologists. Biopsies were obtained from the TI and snap-frozen at $-80^{\circ} \mathrm{C}$ within 30 minutes for RNA and protein analysis, or put in Hank's Balanced Salt Solution (HBSS) for ex vivo experiments.

\section{Total RNA extraction and reverse transcription PCR}

TI biopsies were homogenized in Trizol (catalogue number 15596026; Life Technologies, Burlington, ON, Canada) and RNA extraction was done with Qiagen RNeasy Kit (catalogue number 74104; Qiagen, Mississauga, ON, Canada). After quantification with Nano-Drop ND-1000 Spectrophotometer (Thermo Fisher Scientific, Wilmington, DE, USA), Quantitect Reverse Transcription kit (catalogue number 205311; Qiagen) was used for reverse transcription of $500 \mathrm{ng}$ of RNA. The complementary DNA was used to conduct quantitative real-time-PCR on 7900HT Fast Real Time PCR System (Applied Biosystems, Foster City, CA, USA). The PCR cycle settings were polymerase activation at $50^{\circ} \mathrm{C}$ for 2 minutes, initial denaturing of template DNA for 10 minutes at $94^{\circ} \mathrm{C}$, 35 denaturing cycles for 15 seconds at $95^{\circ} \mathrm{C}$, annealing at $58^{\circ} \mathrm{C}$ for 15 seconds, and elongation at $72^{\circ} \mathrm{C}$ for 30 seconds. Relative quantification was done to compare changes in the gene expression among non-IBD and IBD patients, and glyceraldehyde phosphate dehydrogenase $(G A P D H)$ was used in the experiment as a housekeeping gene. ${ }^{20}$ Gene expressions of $I K K \beta$ (Roche Diagnostics, Mississauga, ON, Canada), $A 20{ }^{21}$ $A B I N-1,{ }^{22}$ and $T A X 1 B P 1^{23}$ were determined with the $2^{-\triangle A C T}$ method (for the primers used, see Table 1).

\section{A20 protein quantification}

A20 protein levels in the biopsies and T84 cells were quantified using an A20 enzyme-linked immunosorbent assay (ELISA) kit (catalogue number EKU08486; Biomatik, Cambridge, ON, Canada), following the manufacturer's
Table I Primers for quantitative reverse transcription polymerase chain reaction

\begin{tabular}{ll}
\hline Target gene & Primers \\
\hline GAPDH & 5'-CATCACTGCCACTCAGAAGA-3' \\
& 5'-AAGTCACAGGAGACAACCG-3' \\
IKK $\beta$ & 5'-AATGGAGCAGGCTGTGGA-3' \\
& 5'-CATGGGGCTCCTCTGTAAGT-3' \\
A20 & 5'-GAGAGCACAATGGCTGAACA-3' \\
& 5-'TCCAGTGTGTATCGGTGCAT-3' \\
ABIN-I & 5'-AAATCCAAATCAGAGCTCCCAA-3' \\
& 5'-CAAATGACACAATCTGGTCTCACT-3' \\
TAXIBPI & 5'-TGCAGCC AGCCTGCTCGAAACTTTA-3' \\
& 5'-TGGAGGATCAGGA GCAGTAGGCACA-3' \\
\hline
\end{tabular}

instructions. The kit is specific for human tissue homogenates, plasma, serum, and other biologic fluids, with a detection range of $78-5000 \mathrm{pg} / \mathrm{mL}$. In addition to testing the kit on both TI and duodenum biopsies, we also tested it on human serum, which further validated the sensitivity of the kit.

\section{Cytokine analysis}

Cytokine analysis of TI biopsies was done using the V-Plex proinflammatory panel 1 kit (Mesoscale Diagnostics, Rockville, MD, USA). Cytokine profiles of interferon $\gamma$, interleukin (IL)-1 $\beta$, IL-2, IL-4, IL-6, IL-8, IL-10, IL-12p70, IL-13, and TNF- $\alpha$ were analyzed with this kit and reported relative to standard curves. ${ }^{24}$

\section{Immunofluorescence microscopy}

Biopsy samples obtained from the TI were mounted in the optimum cutting temperature tissue embedding media (Leica Biosystems, Concord, ON, Canada). Tissue sections were cut $5 \mu \mathrm{m}$ thick by cryotome, embedded on slides, and slides were frozen at $-80^{\circ} \mathrm{C}$. Slides were then fixed for 10 minutes in icecold acetone, washed 3 times in $1 \times$ PBS, and incubated for 1 hour at room temperature in blocking buffer $(10 \%$ normal goat serum). After washing again in PBS, slides were incubated with anti-TNFAIP3 (A20) antibody (catalogue number: ab111192; Abcam, Toronto, ON, Canada) and anti-phosphoA20 S381 antibody, kindly provided by Dr. Derek Abbott (Case Western Reserve University, Cleveland, OH, USA), ${ }^{17}$ at a dilution of $1: 200$, at $4^{\circ} \mathrm{C}$ overnight. Slides were washed again with PBS and stained with Alexa 546 goat anti-mouse secondary antibody (red) and Alexa 488 goat anti-rabbit (green) for 1 hour after being diluted at 1:300 (Thermo Fisher Scientific). After the staining, 4',6-diamidino-2-phenylindole 
(DAPI; Thermo Fisher Scientific) was used to incubate the slides for 1 minute after rinsing in PBS, followed by mounting with Fluorsave (Millipore, Etobicoke, ON, Canada). Slides were viewed with the Zeiss Axio Observer.Z1 microscope using the ZEN Imaging software (Carl Zeiss Canada Ltd., North York, ON, Canada). Immunofluorescence staining of the tissues was observed using the $561 \mathrm{~nm}$ laser filter for A20 staining (red), phospho-A20 (green), and the $405 \mathrm{~nm}$ laser for DAPI (blue). All images were obtained at $60 \times$ magnification. Quantitative measurement of immunofluorescence was conducted with ImageJ as follows, in a blinded manner. After setting the thresholds for the three dyes, three areas of consistent staining, each measuring $20 \times 20 \mu \mathrm{m}$, were analyzed from each image and staining for DAPI, anti-A20, and antiphospho-A20 was calculated per the threshold settings. The percent of the areas positive for A20 and phopho-A20 was calculated by dividing the positively stained areas by the total area analyzed. The mean of all areas measured for each patient sample was reported in the results.

\section{Cell culture}

T-84, human colorectal cell line, derived from a lung metastasis, obtained from ATCC (American Type Culture Collection, Manassas, VA, USA), was chosen for in vitro experiments as it expresses A20 and is commonly used to model immune stimulation in vitro. ${ }^{25,26}$ Cells were cultured in Dulbecco's modified Eagle's medium (DMEM) at $37^{\circ} \mathrm{C}$ in $5 \% \mathrm{CO}_{2}$ with $1 \%$ penicillin/streptomycin and $10 \%$ fetal bovine serum (FBS). The medium was changed on alternate days and cells were passaged every week when confluent. Cells were seeded at a density of $1 \times 10^{6}$ cells per $\mathrm{cm}^{2}$ in 24 -well plates and grown to confluence for 5 days for infection experiments.

\section{Bacterial strains and reagents}

Adherent invasive E. coli, strain LF82, ${ }^{27}$ and E. coli, lab strain HB101, were used for the ex vivo biopsy and T-84 cell assays. Both strains were cultured in Luria-Bertani broth overnight at $37^{\circ} \mathrm{C}$ prior to the inoculation with the biopsies or cell line. TNF- $\alpha, 1 \mathrm{ng} / \mathrm{mL},{ }^{28}$ and lipopolysaccharide (LPS), $10 \mu \mathrm{g} / \mathrm{mL},{ }^{29}$ were used as positive controls to stimulate A20.

\section{Infection of T-84 cells}

T-84 cells were inoculated with either the $E$. coli strains, LF82, or HB101 (suspensions containing $1 \times 10^{8}$ colonyforming units), TNF- $\alpha(1 \mathrm{ng} / \mathrm{mL})$, or LPS $(100 \mathrm{ng} / \mathrm{mL})$ in duplicates. Infected cells were incubated at $37^{\circ} \mathrm{C}, 5 \% \mathrm{CO}_{2}$ for 4 hours, after which epithelial cells were collected and stored at $-80^{\circ} \mathrm{C}$ for RNA extraction using Qiagen RNeasy Kit (Qiagen), and protein extraction.

\section{Ex vivo infection of human TI biopsies}

Ex vivo infection was performed using methods described previously, with modifications. ${ }^{30}$ TI biopsies obtained from non-IBD and CD patients during endoscopy were immediately placed in HBSS on ice and then incubated with DMEM containing $10 \%$ FBS and penicillin/streptomycin $(1 \mathrm{mg} / \mathrm{mL})$ for 1 hour to kill resident bacteria. Biopsies were then washed, medium was changed to antibiotic-free, and samples inoculated with either $E$. coli strains, LF82 or HB101, or TNF- $\alpha$ at the same concentrations as used for the T-84 cells for 10 hours. mRNA (using the Qiagen RNeasy Kit [Qiagen]) and protein were extracted from the samples at the end of the incubation period.

\section{NF- $\kappa \beta$ ELISA}

Cellular extraction before conducting the assay was done using the Cell Extraction Buffer and nuclear fractions were obtained, following standard procedures (Invitrogen, Burlington, ON, Canada). To quantify NF- $\kappa \beta$ stimulation with treatment of the ex vivo biopsies and T-84 cells, an ELISA of the NF- $\kappa \beta-65$ transcription activation domain was conducted using an NF- $\kappa \beta-65$ kit (Invitrogen), on the nuclear fractions.

\section{Statistical analysis}

Data analysis was done with Graph Pad Prism (GraphPad Software Inc., La Jolla, CA, USA), and Mann-Whitney and Student's $t$-test tests were used. The relative quantification values were analyzed using the $2^{\Delta \mathrm{CT}}$ method. To test for correlation, Pearson's correlation coefficient was used. $P<0.05$ was considered to be statistically significant.

\section{Results}

\section{Patients}

A total of 45 patients were screened and consented for this study. Complete data are available for 39 patients, including $15 \mathrm{CD}, 10 \mathrm{UC}$ patients, and 14 non-IBD controls (four controls and two UC patients were excluded as A20 expression could not be detected). We intentionally included both new-onset and established cases to represent the spectrum of disease severity (active and in remission) and to facilitate recruitment. Of the $\mathrm{CD}$ cohort, seven patients were newly diagnosed and eight were previously diagnosed. Of the UC patients, nine were follow-up cases and one was a new case. Patient characteristics are described in Table 2. 
Table 2 Patient characteristics

\begin{tabular}{|c|c|c|c|c|}
\hline Demographic & Non-IBD $(n=14)$ & $C D(n=15)$ & $U C(n=10)$ & $P$-value \\
\hline Sex (M) & 8 & 7 & 4 & \\
\hline New onset/follow-up & N/A & $7 / 8$ & $1 / 9$ & \\
\hline Age (years), mean \pm SEM & $12 \pm 1.8$ & $12.85 \pm 1.1$ & $13.44 \pm 1.1$ & $0.25 * *$ \\
\hline CRP* (normal: $<76.1904 \mathrm{nmol} / \mathrm{L})$, mean \pm SEM & & $149 \pm 64.58$ & $29.52 \pm 8.8$ & 0.8 \\
\hline ESR* (normal: 0-I5 mm/h), mean \pm SEM & & $26 \pm 7.0$ & $9.5 \pm 6.3$ & 0.74 \\
\hline Disease activity: PCDAI for CD. PUCAI for UC* (remission: $<10$ ), mean \pm SEM & $\mathrm{N} / \mathrm{A}$ & $21.36 \pm 3.2$ & $19.9 \pm 4.6$ & \\
\hline \multicolumn{5}{|l|}{ Treatments at time of endoscopy } \\
\hline 5-aminosalicylic acid & - & $\mathrm{I}(6 \%)$ & $\mathrm{I}(10 \%)$ & \\
\hline Sulfasalazine & - & $\mathrm{I}(6 \%)$ & $\mathrm{I}(10 \%)$ & \\
\hline Prednisone & - & I (6\%) & $\mathrm{I}(10 \%)$ & \\
\hline Azathioprine & - & $2(13 \%)$ & $2(20 \%)$ & \\
\hline Methotrexate & - & I (6\%) & $\mathrm{I}(10 \%)$ & \\
\hline Infliximab & - & $4(26 \%)$ & $3(30 \%)$ & \\
\hline
\end{tabular}

Notes: *All data reflect status around time of endoscopy. ${ }^{* *}$ No significant difference between all groups.

Abbreviations: CD, Crohn disease; CRP, C-reactive protein; ESR, erythrocyte sedimentation rate; $f$, female; IBD, inflammatory bowel diseases; $m$, male; N/A, not applicable; PCDAl, Pediatric Crohn Disease Activity Index; PUCAI, Pediatric Ulcerative Colitis Activity Index; UC, ulcerative colitis.

\section{A20 mRNA expression is increased in the $\mathrm{TI}$ of $\mathrm{CD}$ patients and correlates with TNF- $\alpha$ and inflammatory markers}

Both A20 gene expression and TNF- $\alpha$ levels were significantly higher in the TI tissue of $\mathrm{CD}$ patients as compared to $\mathrm{UC}$ and non-IBD patients (Figure $1 \mathrm{~A}$ and $\mathrm{B}$, respectively; $P<0.05$ ) and were positively correlated (Figure $1 \mathrm{C}$ ). All other measured cytokines showed no significant difference (data not shown), suggesting that A20 expression is selectively increased in the presence of high TNF- $\alpha$, as expected. A20 gene expression in TI biopsies also correlated with the objective serum inflammatory markers erythrocyte sedimentation rate and C-reactive protein, but not with the mostly symptombased activity index, Pediatric Crohn Disease Activity Index (Figure 1D).

\section{A20 protein levels are reduced and A20-regulating factors are altered in $\mathrm{TI}$ biopsies from $C D$ patients}

Given that changes in A20 were observed only in CD patients, subsequent analyses did not include UC patients. Surprisingly, tissue levels of A20 protein, as quantified by ELISA, were significantly lower in CD patients than in UC and non-IBD patients (Figure $2 \mathrm{~A} ; P<0.05$ ), despite the higher gene expression. Immunofluorescence quantification of the tissue sections using ImageJ showed that areas where A20 was positive were significantly less in $\mathrm{CD}$ patients as compared to non-IBD patients (Figure 2B; representative images, Figure $2 \mathrm{C} ; P<0.05)$. Percent of intestinal areas positive for S381 phospho-A20 also appeared to be less in CD patients; however, this did not reach significance (Figure 2D; $P=0.33$ ). $I K K \beta$ expression was unchanged among non-IBD and $\mathrm{CD}$ patients (Figure 2E). TAX1BP1 expression was significantly higher in $\mathrm{CD}$ cases (Figure 2F; $P<0.05$ ), whereas $A B I N-1$ expression was significantly lower in $\mathrm{CD}$ patients relative to non-IBD cases (Figure 2G; $P<0.05$ ). These findings suggest that alterations in factors regulating A20 could explain the difference between $A 20$ gene expression and protein levels.

\section{E. coli LF82 treatment increased A20 expression but did not affect $\mathrm{A} 20$ protein levels in T84 cells}

As we found a striking discrepancy between $A 20$ gene expression and A20 protein levels in the TI of CD patients, and as bacteria are altered in IBD and could impact immune responses ${ }^{31}$ we hypothesized that bacteria could possibly be a contributing factor that affects A20 stability and action, ${ }^{32}$ and explored this possibility by conducting infection experiments on a T84 cell culture model and on ex vivo biopsies.

The outcome we chose to confirm if the NF- $\kappa \beta$ pathway was activated was quantification of translocation of the $\mathrm{p} 65$ $\mathrm{NF}-\kappa \beta$ subunit on nuclear fractions, extracted from the cells and biopsies (we confirmed that bacterial infection and incubation with the positive control, TNF- $\alpha$, did indeed lead to activation of NF- $\kappa \beta ; P<0.05$; Figure $\mathrm{S} 1$ ).

As adherent-invasive E. coli (AIEC) is linked to CD patients, ${ }^{33}$ we incubated T- 84 cells with the AIEC strain LF82, or, alternatively, commensal E. coli HB101, as well as TNF- $\alpha$ and LPS as positive controls. A20 gene expression was significantly higher in LF82-treated vs. untreated cells 
A

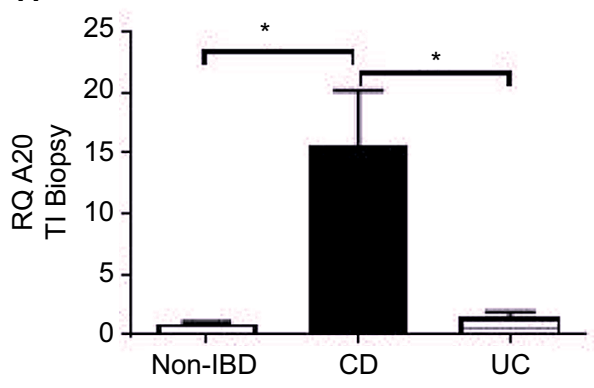

C

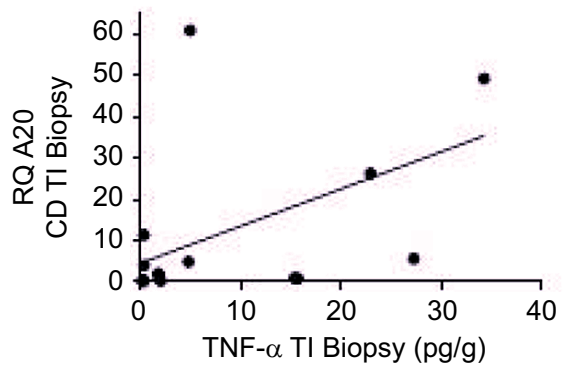

B

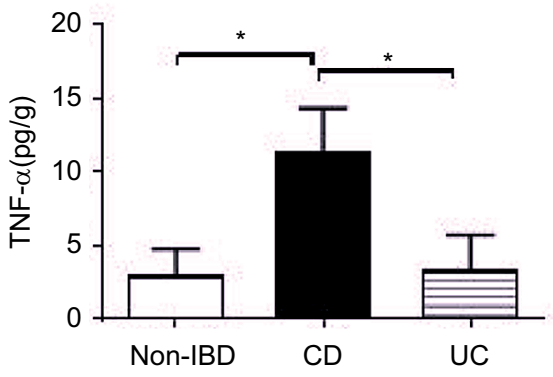

D

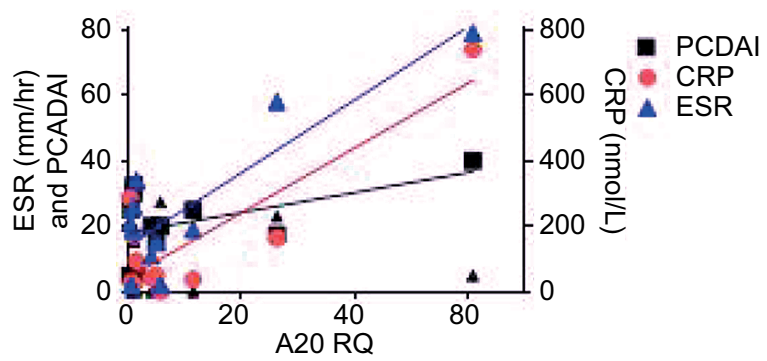

Figure I Elevated A20 expression TI of CD patients; A20 expression correlates with TNF- $\alpha$ and inflammatory markers.

Notes: Quantification of $A 20$ gene expression and TNF- $\alpha$ levels was conducted on TI biopsies. (A) A20 expression was significantly higher in CD patients as compared to non-IBD and UC patients (RQ for non-IBD: $0.91 \pm 0.15$; CD: $15.5 \pm 4.6$; UC: I.4 \pm 0.46 , analysis of variance, $P<0.05$ ). (B) Cytokine analysis performed on TI biopsies of patients showed significantly higher TNF- $\alpha$ levels in the TI of CD patients as compared to non-IBD and UC patients (non-IBD: $3.0 \pm I .7$; CD: II.4 2.9 , UC: 3.4 \pm 2.3 pg/g. Mann-Whitney test: $P<0.05 ; n=14$ non-IBD controls, $15 \mathrm{CD}$, and $10 \cup C$ patients). (C) A20 expression in TI biopsies of CD patients correlated positively with biopsy TNF- $\alpha$ levels (Pearson's “ $r$ ": 0.5, $P<0.05$ ). (D) $A 20$ gene expression in TI biopsies is positively correlated with serum CRP and ESR (CRP; Pearson's $r$ coefficient $=0.80, P<0.05$. ESR; Pearson's $r$ coefficient $=0.87,<0.05$ ). A20 expression did not correlate with PCDAI (Pearson's $r$ coefficient $=0.5, P=0.10$ ). *Significant difference.

Abbreviations: CD, Crohn disease; CRP, C-reactive protein; ESR, erythrocyte sedimentation rate; IBD, inflammatory bowel diseases; TI, terminal ileum; TNF- $\alpha$, tumor necrosis factor- $\alpha$; UC, ulcerative colitis; PCDAI, Pediatric Crohn Disease Activity Index.

(Figure $3 \mathrm{~A} ; P<0.05)$. Notably, in contrast to gene expression, A20 protein levels after inoculation with LF82 were not elevated (Figure 3B, $P>0.05$ ). Other A20-regulating genes, IKK $\beta$, TAX1BP1, and ABIN-1, were unaffected by infection in vitro (Figure $\mathrm{S} 2$ ).

\section{LF82 infection of ex vivo TI biopsies from CD patients increased A20 gene expression but did not alter $\mathrm{A} 20$ protein levels and ABIN-I expression}

To confirm the in vitro findings, we collected fresh TI biopsies during endoscopy and treated them with $E$. coli strains LF82 or HB101, or with TNF- $\alpha$ to define the effects of microbes on A20 regulation. Supporting our findings in biopsies and cell culture, treatment of TI biopsies taken from CD patients with LF82 and TNF- $\alpha$ significantly increased A20 expression, compared to untreated biopsies and those treated with commensal HB101 (Figure 3C, $P<0.05$ ). In contrast, A20 protein levels did not increase after treatment with LF82, compared to TNF- $\alpha$ and the untreated biopsies (Figure 3D). This indicates a similar trend to that observed in TI biopsies (Figures 1A and 2A), although the difference there reached significance.

$I K K \beta$ expression was also higher after treatment with LF82 compared to the untreated group $(P<0.05)$. TAX1BP1 expression increased slightly (but not significantly) with treatment by both $E$. coli strains and TNF- $\alpha$. While TNF- $\alpha$ treatment did cause a moderate, nonsignificant increase in $A B I N-1$ expression, LF82 did not affect this factor (Figure S3).

Supporting the specificity of our findings, infection or TNF- $\alpha$ treatment of TI biopsies of non-IBD patients did not alter gene expression or A20 protein levels $(P>0.05$; Figure S4). Of note, the basal expression level of all genes was low in biopsies from non-IBD cases.

Our in vitro and ex vivo results further validate the findings in TI biopsies of CD patients, suggesting that inflammation increases A20 gene expression, as expected, but without an increase in A20 protein levels, possibly through bacterial (LF-82 in this case)-mediated attenuation of ABIN-1. This 
A

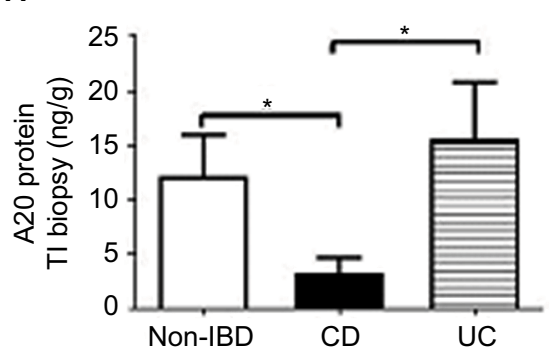

C

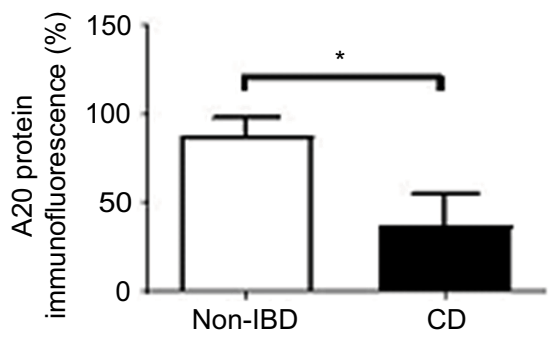

E

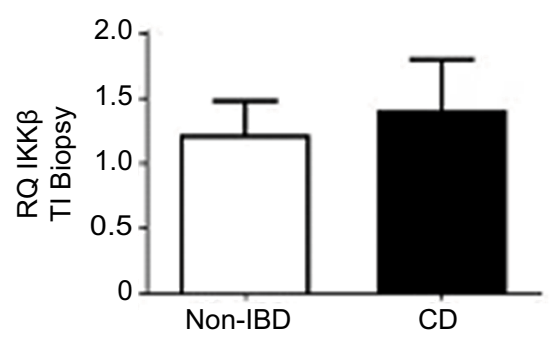

B

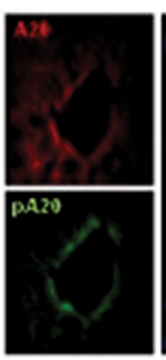

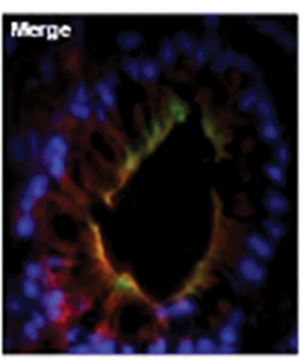

Non-IBD

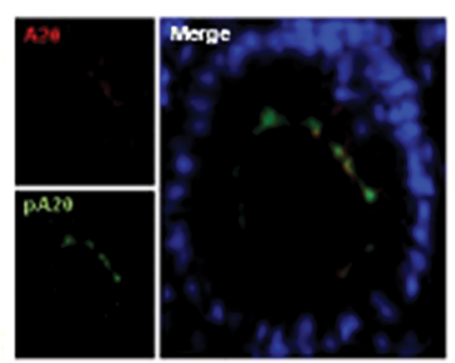

Crohn disease
D

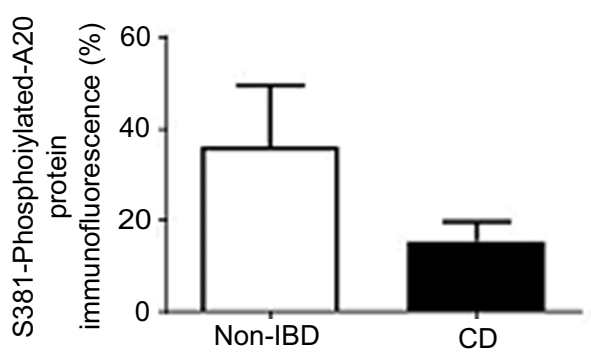

F

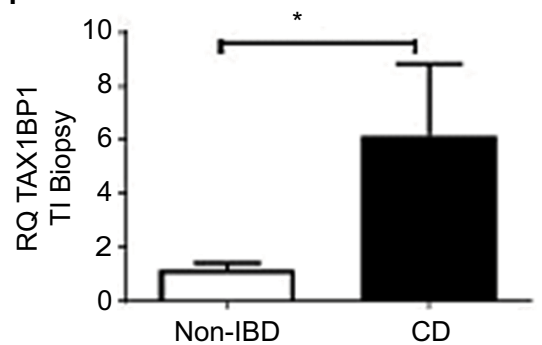

Figure 2 A20 protein levels are reduced and A20-regulating factors altered in TI biopsies from CD patients.

Notes: A20 protein levels were quantified in TI biopsies of patients using ELISA. *Significantly different. (A) A20 protein levels in TI biopsies of CD patients were

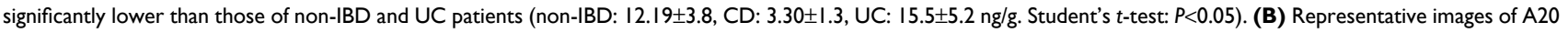
immunofluorescence in TI of non-IBD and CD patients show the presence of A20 in the tissue. Red color indicates A20 antibody, green denotes phospho-A20 antibody, and blue staining is for DAPI. All images were obtained at $60 \times$ magnification. (C) Quantification of A20 antibody immunofluorescence using Image analyses showed a significant reduction in $A 20$ staining in biopsies of $C D$ patients (non-IBD: $87.83 \pm 10.19$; $C D$ : $37.28 \pm 17.85$. Mann-Whitney test: $P<0.05$, $n=6$ ). (D) There was a trend for reduction in $\mathrm{TI}$ areas positive for S38I phospho-A20 in CD patients as compared to non-IBD patients (non-IBD: 36 \pm I3.45; CD: I5.5 \pm 4.24 ; Mann-Whitney test: $P>0.05$, $\mathrm{n}=6$ ); (E) IKK $\beta$ expression was unchanged between non-IBD and CD patients (non-IBD: I.2I \pm 0.3 ; CD: I.3 \pm 0.4 ). (F) TAXIBPI expression was significantly higher in CD patients as compared to non-IBD cases (non-IBD: I.I \pm 0.23 ; $C D$ : 6.I7 \pm 2.6 ; Mann-Whitney test: $P<0.05$ ). (G) $A B I N-I$ expression was significantly lower in $C D$ patients as compared to non-IBD cases (non-IBD: I.4 \pm 0.4 ; CD: $0.4 \pm 0.3$; Mann-Whitney test: $P<0.05$ ).

Abbreviations: CD, Crohn disease; IBD, inflammatory bowel diseases; TI, terminal ileum; UC, ulcerative colitis.

is important as ABIN-1 acts as a chaperone to A20, helping it to regulate the IKK/NEMO complex, and its downregulation/absence attenuates A20 activity. ${ }^{13}$ As a result, A20 does not suppress the NF- $\kappa \beta$ response, possibly contributing to the proinflammatory state seen in CD.

\section{Discussion}

The inability to control inflammation is a central feature of IBD and poses a great challenge toward establishing safe and effective treatments. Modulation of inflammation-associated factors with potential to suppress inflammation in a specific way is a critical, and yet to be utilized, step to optimize treatment strategies.
A20 is a "natural" inhibitor of NF- $\kappa \beta$ inflammation. ${ }^{34}$ Our objective was to study A20 and its associated factors in pediatric CD with the goal of identifying abnormalities in immune regulation and finding novel approaches to control inflammation. We focused on pediatric patients because they present with more extensive disease and are less likely to have comorbidities or to be on other treatments, resulting in a more uniform and "clean" phenotype; ${ }^{35}$ however, given that most of our patients are over the age of 10 , they are likely to be genetically similar to adult IBD patients.

Gene expression and protein profiling of biopsies from non-IBD and IBD patients showed contrasting and unexpected results. We found that although $A 20$ gene expression 
A

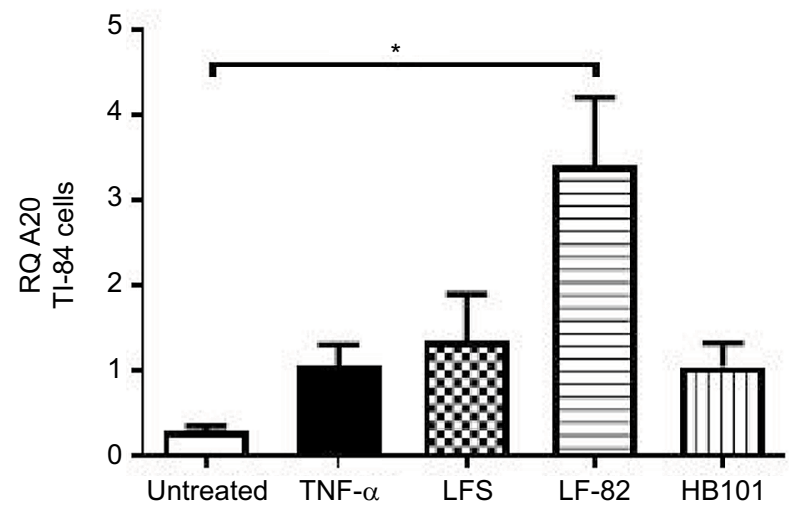

C

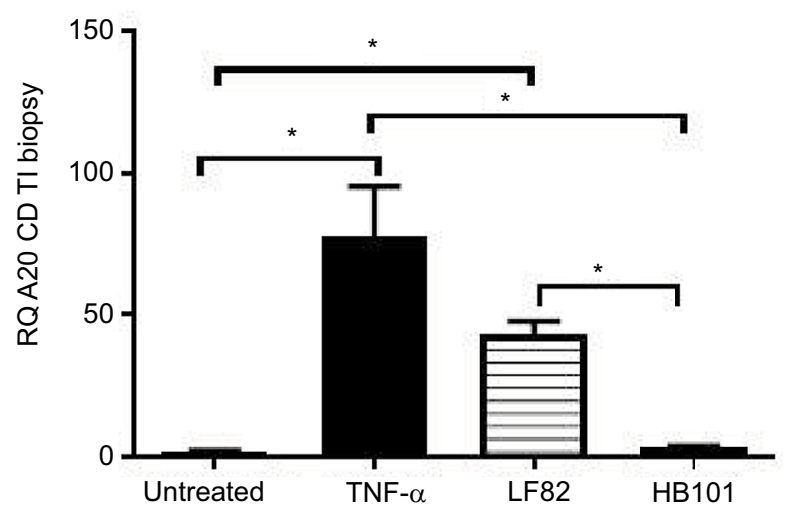

B

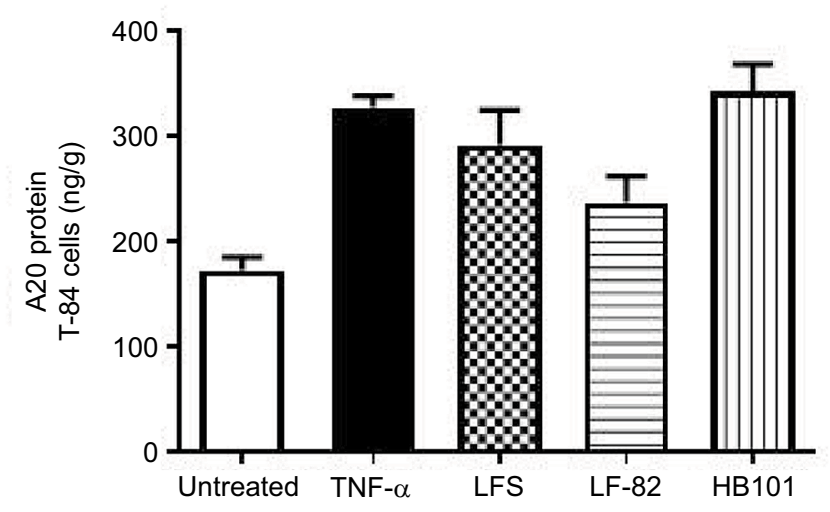

D

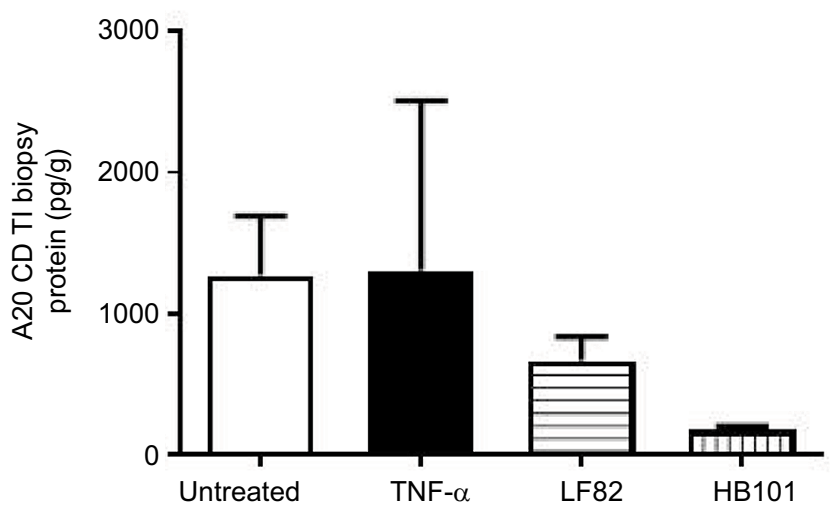

Figure 3 LF82 treatment of T84 cells, biopsies from CD patients increased A20 expression, not A20 protein.

Notes: T84 cells were subjected to treatment either with the $E$. coli strains, LF82 or HBI0I, or TNF- $\alpha$ or LPS, as positive controls. *Significantly different. (A) A20 expression after treatment with LF82 was significantly higher than untreated cells (LF82: $3.5 \pm 0.8$; TNF- $\alpha$ : I.05 \pm 0.2 ; LPS: I.3 \pm 0.5 ; HBI0I: I.03 \pm 0.2 ; untreated: $0.28 \pm 0.05$. Student's $t$-test, $P<0.05 ; n=7)$. (B) A20 protein levels did not differ significantly among all groups. TI biopsies from CD patients were incubated with either the $E$. coli strains LF82 or HBIOI or with TNF- $\alpha$. (C) Treatment with LF82 and TNF- $\alpha$ caused a significant increase in A20 gene expression as compared to the untreated biopsies (LF82: 42.9 44.7; TNF- $\alpha$ : 77.27 \pm 18.02, HBI0I: 3. \pm 0.56 ; untreated: 1.99 \pm 0.35 , Mann-Whitney test, $P<0.05, n=4)$. (D) A20 protein levels did not differ significantly among all groups. Abbreviations: CD, Crohn disease; LPS, lipopolysaccharide; TI, terminal ileum; TNF- $\alpha$, tumor necrosis factor- $\alpha$.

was increased in CD patients, A20 protein levels were significantly lower than in non-IBD and UC patients. Thus, focusing further analyses on CD patients, we explored potential factors that could affect A20 post-translationally and negate its function/stability. Our results show that $A B I N-1$ expression was significantly lower in $C D$ patients, which possibly decreased the ability of A20 to bind to its substrates and inhibit inflammation. As well, the decreased $I K K \beta$ could possibly contribute to degradation of A20, as the IKK $\beta$-mediated S381 phosphorylated state stabilizes A20 $1{ }^{17}$ Our results show that although the difference is not statistically significant, phosphorylated A20 appears decreased in TI biopsies of CD patients than in non-IBD patients.

We speculated that bacteria may be affecting A20's stability as a protein and assessed this by conducting mechanistic experiments on T-84 cells and ex vivo TI biopsies. To do this, we inoculated two $E$. coli strains, LF82, which is associated with disease recurrence in CD patients, and nonpathogenic, commensal HB101, onto T-84 cells and TI biopsies from $\mathrm{CD}$ and non-IBD patients to characterize the direct effects of bacteria on A20 and its regulation. E. coli strains have been shown to enhance responses by the immune system and increase $A 20$ expression. ${ }^{32}$ We saw a similar effect, as treatment of T84 cells with LF82 induced a significant increase in A20 gene expression. The expression of other, related genes was only minimally increased. Remarkably, and similar to our findings in patient biopsies, A20 protein levels were not increased in the LF82-treated group despite the increase in gene expression, again suggesting a dislink between gene expression and protein level/function.

Ex vivo inoculation of TI biopsies from $\mathrm{CD}$ patients with LF82 showed a significantly higher increase in $A 20$ 
expression, as well as increases in $I K K \beta$ and possibly $T A X 1 B P 1$ expressions. In keeping with the findings in patients, there was no increase in $A B I N-1$ or A20 protein levels with LF82 treatment. Treatment of non-IBD biopsies did not cause a change in the gene expression or protein profile.

We had not analyzed the microbial composition of the TI biopsies; thus, we are unable to speculate if LF82 bacteria were already present in the $\mathrm{CD}$ biopsies and could be lowering A20 protein levels; however, we had incubated all biopsies with antibiotics prior to experiments to kill resident bacteria, and biopsies from both non-IBD and CD patients were subjected to the same bacterial load and experimental conditions. It is, therefore, possible that LF82 acts more in the setting of established inflammation and is not significantly virulent without existing dysbiosis or disrupted homeostasis.

Our experimental assays show that LF82 caused, in the in vitro or ex vivo setting, effects that were similar to those seen in TI tissue from patients; we, therefore, speculate that some yet undefined, microbial factors could be leading to dysregulation between A20 expression and protein, as well as attenuating the effect of other A20 regulating genes, particularly $A B I N-1$, which could contribute toward lower A20 protein levels and an inability to suppress NF- $\kappa \beta$-driven inflammation. Several factors could explain the discordance between A20 expression and protein levels. While untested in our study, it is possible that some of our patients could have mutations in A20 or related genes, leading to reduced transcription. A20 could also have been affected post-translationally through other mechanisms, resulting in low A20 protein levels because of reduced protein stability. Our work focused on several A20-associated genes that could impact protein stability. The expression of ABIN-1 was significantly decreased in $\mathrm{CD}$ patients, which could have potentially decreased the stability and the ability of A20 to bind to its target substrates and inhibit inflammation. IKK $\beta$ could have also possibly contributed to the degradation of A20, as the phosphorylated state stabilizes A20, ${ }^{17}$ although its expression was unchanged in our study. A20's progression to or stability as a protein could be markedly affected by bacteria as the E. coli strain LF82 showed a significant increase in A20 expression but reduced protein levels in experiments. Indeed, previous studies have reported that nonpathogenic E. coli strains stimulate the immune response and increase A20 expression. ${ }^{32}$

\section{Limitations}

This study has several limitations. First, we had to exclude several non-IBD cases on finding inflammation on endoscopy and histology, which decreased our subject numbers. Second, as A20 basal expression is usually low (in the absence of local inflammation), it could not be detected in the TI of several non-IBD and UC patients (which may have resulted in an underestimation of the true difference between groups). Given the limitation in tissue availability, we were limited in the number of proteins/genes we could analyze. We were also unable to analyze the kinetics of A20 protein post-translationally, such as its degradation rate and stability, and possible variations in its binding with ABIN-1 protein in in vivo and ex vivo experiments. There are several other factors that affect the A20 protein and have not been addressed in this study, such as paracaspase MALT-1, which cleaves cytosolic A20, and reactive oxygen species. ${ }^{34}$ Regarding the protective mechanisms of this pathway, one mechanism is the "auto shut-off" inhibitory signal for NF- $\kappa \beta$, mediated by I $\kappa \mathrm{B} \alpha$, which terminates the inflammatory response by binding to NF- $\kappa \beta$ complexes and shuttles them back into the cytoplasm. Also, in addition to A20, cylindromatosis is a deubiquinating protein that could inhibit the inflammation propagated through this pathway. ${ }^{36}$ These factors could not be analyzed in our study because of limited tissue sample.

While we have not been able to identify the bacterial factor or mechanism for A20 dysregulation, our findings suggest a novel mechanism for uncontrolled gut inflammation in IBD and that controlling changes in microbes, together with reducing inflammation, could help to restore homeostasis in the gut in CD.

Our results have shown two important findings: first, the presence of high $A 20$ expression and low A20 levels in pediatric $\mathrm{CD}$ patients. This reflects a failure of regulation of inflammation in the gut, through A20, likely due to alterations in control and/or stability of the A20 protein. Second, we have demonstrated a unique role played by LF82 AIEC through its ability to augment $A 20$ expression, but not its associated genes, which could possibly be the reason for lower A20 protein levels in CD patients and the inability to suppress inflammation.

\section{Conclusion}

We have reported for the first time, the importance of A20 dysregulation in pediatric $\mathrm{CD}$ and provided important incentives for future studies focusing on regulation of inflammation in pediatric $\mathrm{CD}$ as a potential novel therapeutic approach. A20 is an important anti-inflammatory protein and steps toward its stability and regulation can be a major player of inflammation control in CD. Our pilot study reports important 
findings regarding A20 in pediatric CD patients, which could function as a baseline to design future studies elucidating molecular mechanisms and kinetics of A20 in IBD patients. Further avenues to be explored should include studies related to the functional aspects of A20, which could help to develop drugs that stimulate A20, prevent the protein's degradation, or counteract the effects of bacteria on the protein. Our findings theoretically support a potential role for some therapeutic approaches, focused on more optimal A20 function as an alternative, novel method to decrease inflammation. In addition to already available TNF- $\alpha$ inhibitors, another potential target could be the paracaspase MALT-1 (which cleaves A20 protein), limiting NF- $\kappa \beta$ effects in IBD. ${ }^{37}$ Polymorphisms in $A 20$ could be used as genetic biomarker to tailor therapy, as functional polymorphisms in $A 20$ were predictive of response to anti-TNF therapy in a Danish cohort of IBD patients. ${ }^{38}$ In another cohort, $A 20$ single-nucleotide polymorphisms correlated with anti-TNF therapy. ${ }^{39}$ The results of these studies imply that polymorphisms in $A 20$ can potentially be used as a genetic biomarker to tailor therapy; however, this notion needs to be analyzed in larger pediatric cohorts.

While our study has revealed important findings related to the discordance between A20 gene and protein levels, additional experiments are needed in future studies to better understand the underlying causative factors. Future studies should include the analysis of mRNA half-life. As several studies have reported direct targeting of A20 by microRNAs, such as miR-12540 and miR-19b, ${ }^{41}$ abolishing its function, understanding the role of microRNAs in the context of A20 function in IBD should also be a future target.

\section{Acknowledgments}

We thank our patients for their participation and the hospital staff for their assistance with the study. Special thanks to Cheryl Kluthe, RN and Pavel Medvedev, EPIC research coordinator, and to Dr Abbott from Case Western Reserve University, Cleveland, USA for his generous provision of the S381-phosphoA20 antibody. The abstract of this work was presented at the World Congress of Pediatric Gastroenterology, Hepatology and Nutrition, October 5-8, 2016, in Montreal, Canada.

\section{Author contributions}

All authors made substantial contributions to conception and design, acquisition of data, or analysis and interpretation of data; took part in drafting the article or revising it critically for important intellectual content; gave final approval of the version to be published; and agree to be accountable for all aspects of the work.

\section{Disclosure}

Eytan Wine, Hien Q Huynh, and Matthew W Carroll are members of the advisory boards of Janssen and AbbVie. The authors report no other conflicts of interest in this work.

\section{References}

1. Eszter Muller K, Laszlo Lakatos P, Papp M, Veres G. Incidence and paris classification of pediatric inflammatory bowel disease. Gastroenterol Res Pract. 2014;2014:Article ID 904307.

2. Benchimol EI, Manuel DG, Guttmann A, et al. Changing age demographics of inflammatory bowel disease in Ontario, Canada: a population-based cohort study of epidemiology trends. Inflamm Bowel Dis. 2014;20:1761-1769.

3. Oeckinghaus A, Hayden MS, Ghosh S. Crosstalk in NF- $\kappa$ B signaling pathways. Nat Immunol. 2011;12:695-708.

4. Hayden MS, Ghosh S. Shared principles in NF-kappaB signaling. Cell. 2008;132:344-362.

5. Atreya I, Atreya R, Neurath MF. NF-kappaB in inflammatory bowel disease. J Intern Med. 2008;263:591-596.

6. Ma A, Malynn BA. A20: linking a complex regulator of ubiquitylation to immunity and human disease. Nat Rev Immunol. 2012;12:774-785.

7. Vereecke L, Sze M, Mc Guire C, et al. Enterocyte-specific A20 deficiency sensitizes to tumor necrosis factor-induced toxicity and experimental colitis. J Exp Med. 2010;207:1513-1523.

8. Bruewer M, Luegering A, Kucharzik T, et al. Proinflammatory cytokines disrupt epithelial barrier function by apoptosis-independent mechanisms. J Immunol. 2003;171:6164-6172.

9. Kolodziej LE, Lodolce JP, Chang JE, et al. TNFAIP3 maintains intestinal barrier function and supports epithelial cell tight junctions. PLoS One. 2011;6(10):e26352.

10. Burczynski ME, Peterson RL, Twine NC, et al. Molecular classification of Crohn's disease and ulcerative colitis patients using transcriptional profiles in peripheral blood mononuclear cells. J Mol Diagn. 2006;8:51-61.

11. Arsenescu R, Bruno MEC, Rogier EW, et al. Signature biomarkers in Crohn's disease: toward a molecular classification. Mucosal Immunol. 2008;1:399-411.

12. Fernandes P, MacSharry J, Darby. Differential expression of key regulators of Toll-like receptors in ulcerative colitis and Crohn's disease: a role for Tollip and peroxisome proliferator-activated receptor gamma? Clin Exp Immunol. 2016;183:358-368.

13. Mauro C, Pacifico F, Lavorgna A, et al. ABIN-1 binds to NEMO/IKKgamma and co-operates with A20 in inhibiting NF-кB. J Biol Chem. 2006;281:18482-18488.

14. Shembade N, Pujari R, Harhaj NS, Abbott DW, Harhaj EW. The kinase IKK $\alpha$ inhibits activation of the transcription factor NF- $\mathrm{KB}$ by phosphorylating the regulatory molecule TAX1BP1. Nat Immunol. 2011;12:834-843.

15. Verstrepen L, Verhelst K, Carpentier I, Beyaert R. TAX1BP1, a ubiquitin-binding adaptor protein in innate immunity and beyond. Trends Biochem Sci. 2011;36(7):347-354.

16. Verstrepen L, Carpentier I, Verhelst K, Beyaert R. ABINs: A20 binding inhibitors of NF- $\mathrm{KB}$ and apoptosis signaling. Biochem Pharmacol. 2009;78:105-114.

17. Hutti JE, Turk BE, Asara JM, Ma A, Cantley LC, Abbott DW. IkappaB kinase beta phosphorylates the K63 deubiquitinase A20 to cause feedback inhibition of the NF-kappaB pathway. Mol Cell Biol. 2007;27:7451-7461.

18. Wertz IE, Newton K, Seshasayee D, et al. Phosphorylation and linear ubiquitin direct A20 inhibition of inflammation. Nature. 2015;528:1-6. 
19. Levine A, Koletzko S, Turner D, et al. ESPGHAN revised porto criteria for the diagnosis of inflammatory bowel disease in children and adolescents. J Pediatr Gastroenterol Nutr. 2014;58:795-806.

20. Bertiaux-Vandaële N, Youmba SB, Belmonte L, et al. The expression and the cellular distribution of the tight junction proteins are altered in irritable bowel syndrome patients with differences according to the disease subtype. Am J Gastroenterol. 2011;106:2165-2173.

21. Liu J, Yang S, Wang Z, Chen X, Zhang Z. Ubiquitin ligase A20 regulates p53 protein in human colon epithelial cells. J Biomed Sci. 2013;20:74.

22. Adrianto I, Wang S, Wiley GB, et al. Association of two independent functional risk haplotypes in TNIP1 with systemic lupus erythematosus. Arthritis Rheum. 2012;64:3695-3705.

23. Gröschl B, Bettstetter M, Giedl C, et al. Expression of the MAP kinase phosphatase DUSP4 is associated with microsatellite instability in colorectal cancer (CRC) and causes increased cell proliferation. Int J Cancer. 2013;132:1537-1546.

24. Wine E, Mack DR, Hyams J, et al. Interleukin-6 is associated with steroid resistance and reflects disease activity in severe pediatric ulcerative colitis. J Crohns Colitis. 2013;7:916-922.

25. Li MY, Zhu M, Zhu B, Wang ZQ. Cholera toxin suppresses expression of ubiquitin editing enzyme A20 and enhances transcytosis. Cell Physiol Biochem. 2013;31:495-504.

26. El-Etr SH, Mueller A, Tompkins LS, Falkow S, Merrell DS. Phosphorylation-independent effects of CagA during interaction between Helicobacter pylori and T84 polarized monolayers. J Infect Dis. 2004;190:1516-1523.

27. Darfeuille-Michaud A, Boudeau J, Bulois P, et al. High prevalence of adherent-invasive Escherichia coli associated with ileal mucosa in Crohn's disease. Gastroenterology. 2004;127:412-421.

28. Fish SM, Proujansky R, Reenstra WW. Synergistic effects of interferon gamma and tumour necrosis factor alpha on T84 cell function. Gut. 1999;45:191-198.

29. Cario E, Rosenberg IM, Brandwein SL, Beck PL, Reinecker HC, Podolsky DK. Lipopolysaccharide activates distinct signaling pathways in intestinal epithelial cell lines expressing Toll-like receptors. J Immunol. 2000;164:966-972.
30. MacCallum AJ, Harris D, Haddock G, Everest PH. Campylobacter jejuni-infected human epithelial cell lines vary in their ability to secrete interleukin-8 compared to in vitro-infected primary human intestinal tissue. Microbiology. 2006;152:3661-3665.

31. Alipour M, Zaidi D, Valcheva R, et al. Mucosal barrier depletion and loss of bacterial diversity are primary abnormalities in paediatric ulcerative colitis. J Crohns Colitis. 2016;10(4):462-471.

32. Zargar A, Quan DN, Carter KK, et al. Bacterial secretions of nonpathogenic Escherichia coli elicit inflammatory pathways: a closer investigation of interkingdom signaling. MBio. 2015;6(2):e00025.

33. Strober W. Adherent-invasive $E$. coli in Crohn disease: bacterial "agent provocateur." J Clin Invest. 2011;121:841-844.

34. Catrysse L, Vereecke L, Beyaert R, van Loo G. A20 in inflammation and autoimmunity. Trends Immunol. 2014;35:22-31.

35. Greef E De, Mahachie John JM, Hoffman I, et al. Profile of pediatric Crohn's disease in Belgium. J. Crohns Colitis. 2013;7(11):e588-e598.

36. Yoshida H, Jono H, Kai H, Li JD. The tumor suppressor cylindromatosis (CYLD) acts as a negative regulator for toll-like receptor 2 signaling via negative cross-talk with TRAF6 and TRAF7. J Biol Chem. 2005;280:41111-41121.

37. Coornaert B, Baens M, Heyninck K, et al. T cell antigen receptor stimulation induces MALT1 paracaspase-mediated cleavage of the NF-kappaB inhibitor A20. Nat Immunol. 2008;9:263-271.

38. Bank S, Andersen PS, Burisch J, et al. Associations between functional polymorphisms in the NFkappaB signaling pathway and response to anti-TNF treatment in Danish patients with inflammatory bowel disease. Pharmacogenomics J. 2014;14:526-534.

39. Vereecke L, Vieira-Silva S, Billiet T, et al. A20 controls intestinal homeostasis through cell-specific activities. Nat Commun. 2014;5:5103.

40. Kim S-W, Ramasamy K, Bouamar H, Lin AP, Jiang D, Aguiar RC. MicroRNAs miR-125a and miR-125b constitutively activate the NF- $\kappa \mathrm{B}$ pathway by targeting the tumor necrosis factor alpha-induced protein 3 (TNFAIP3, A20). Proc Natl Acad Sci USA. 2012;109: 7865-7870.

41. Gantier MP, Stunden HJ, McCoy CE, et al. A miR-19 regulon that controls NF- $\mathrm{BB}$ signaling. Nucleic Acids Res. 2012;40:8048-8058. 


\section{Supplementary materials}

A

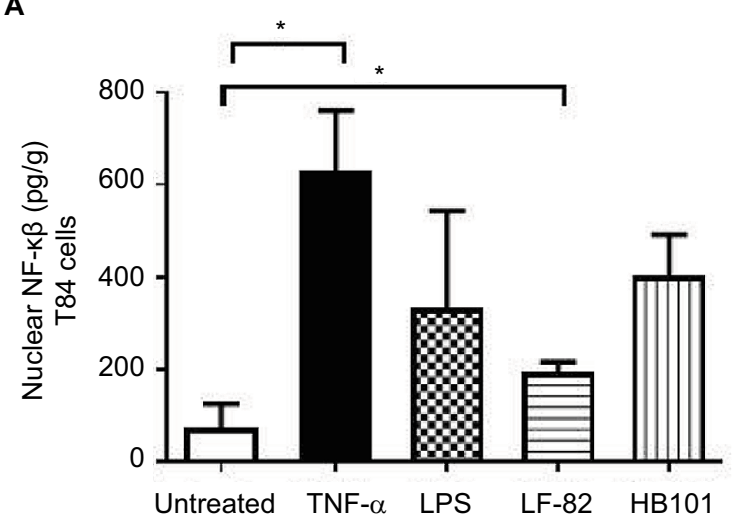

B

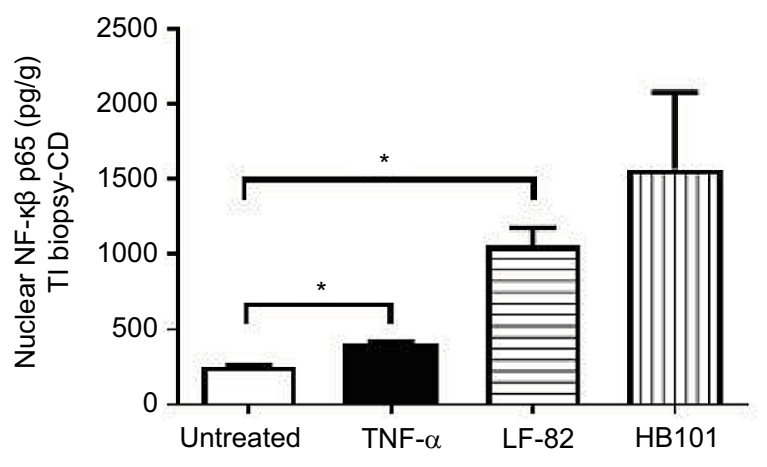

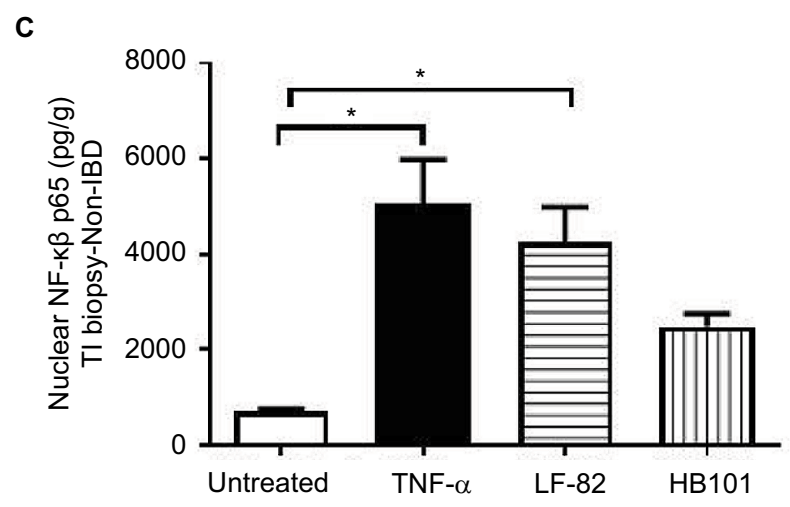

Figure SI Bacterial infection and incubation with the positive control TNF- $\alpha$ lead to activation of NF- $\kappa \beta$.

Notes: NF- $\kappa \beta$ p 65 was stimulated by TNF- $\alpha$ and bacteria after incubation with patient biopsies and T-84 cells and showed increased nuclear translocation as compared to untreated samples. (A) NF- $\kappa \beta$ p65 levels in treated T-84 cells. (B) NF- $\kappa \beta$ p65 levels in treated CD biopsies. (C) NF- $\kappa \beta$ p65 levels in treated non-IBD biopsies. *Significant difference.

Abbreviations: CD, Crohn disease; IBD, inflammatory bowel diseases; NF- $\kappa \beta$, nuclear factor kappa-light-chain-enhancer of activated B-cells; TNF- $\alpha$, tumor necrosis factor- $\alpha$. 
A

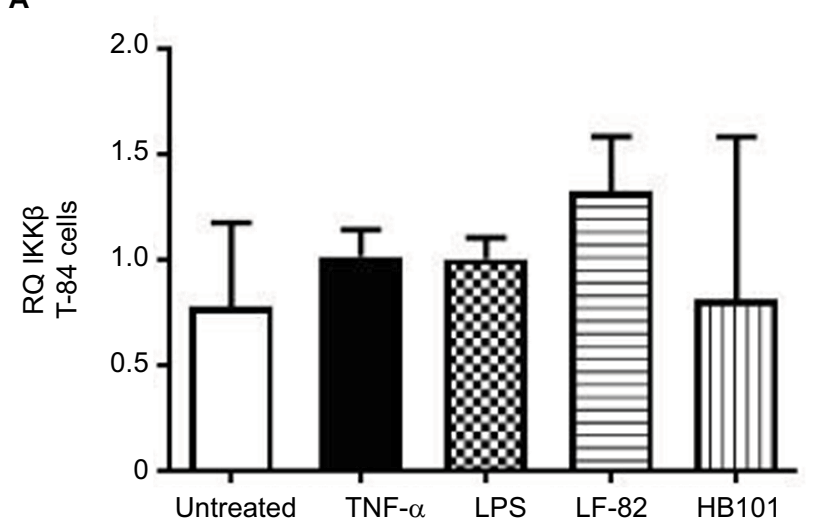

B

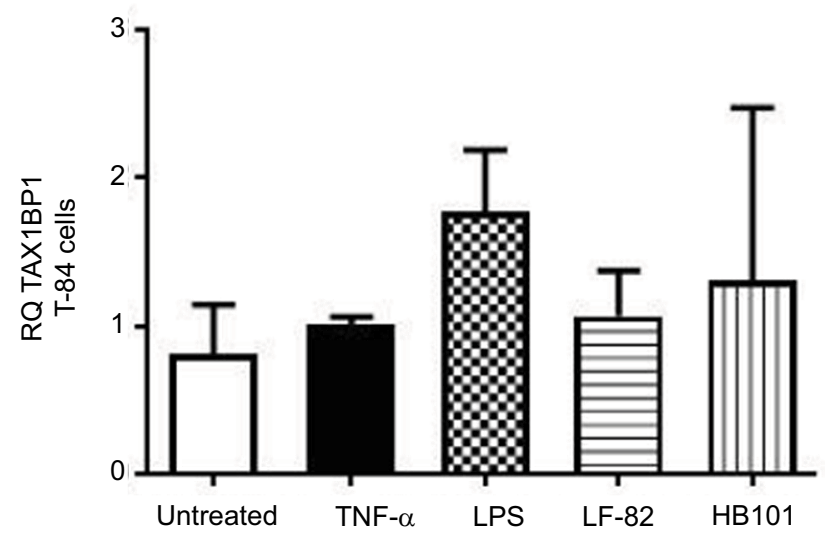

C

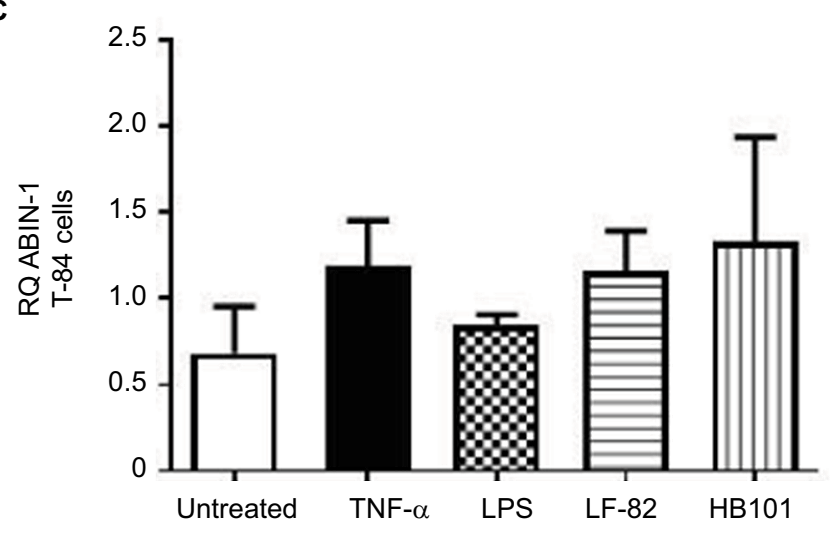

Figure S2 IKK $\beta$, TAXIBPI, and ABIN-I were unaffected by infection in vitro in T-84 cells.

Notes: (A) IKK $\beta$ expression after the treatments was not significantly affected by the treatments (LF82: 1.3 $\pm 0.3 ;$ TNF- $\alpha: 1.0 \pm 0.1 ;$ LPS: $1.0 \pm 0.9 ;$ HBI0I: $0.8 \pm 0.7$; untreated:

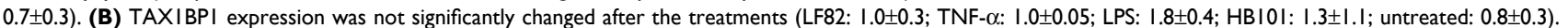
(C) ABIN-I expression did not change significantly (LF82: I.I5 \pm 0.2 ; TNF- $\alpha$ : I.18 \pm 0.2 ; LPS: $0.84 \pm 0.05$; HBI0I: I.3 \pm 0.6 ; untreated: $0.6 \pm 0.2$ ). Abbreviations: LPS, lipopolysaccharide; TNF- $\alpha$, tumor necrosis factor- $\alpha$. 
A

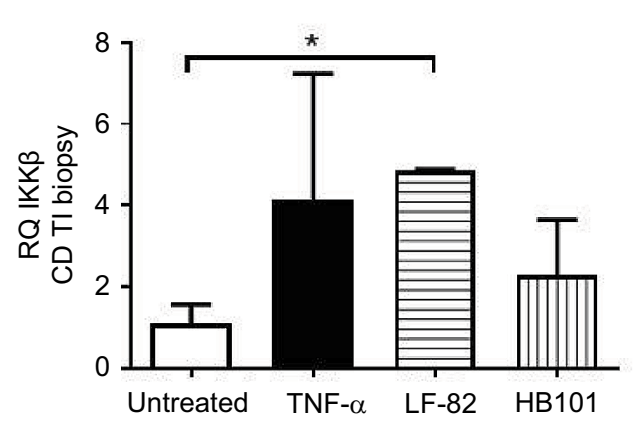

B

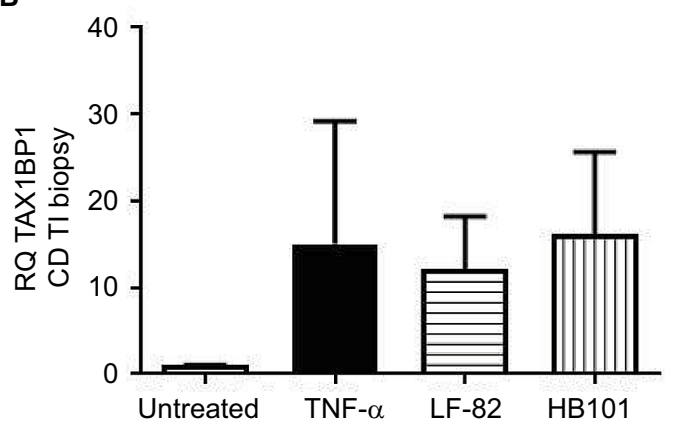

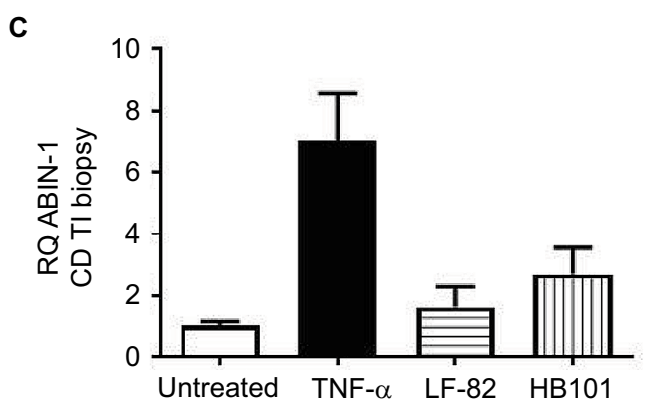

Figure S3 TNF- $\alpha$ treatment caused a moderate, nonsignificant increase in ABIN-I expression of ex vivo TI biopsies of CD biopsies but LF82 did not affect this factor. Notes: (A) IKK $\beta$ expression increased after treatment with LF82 compared to the untreated group (LF82: 4.8 \pm 0.03 ; TNF- $\alpha$ : 4.I4 \pm 3 ; HBI0I: $2.3 \pm I .3 ;$ untreated: I.I \pm 0.4 , Mann-Whitney test, $P<0.05)$. (B) TAXIBPI expression was not statistically increased, but trended to be higher by treatment by both $E$. coli strains and TNF- $\alpha$ (LF82: I2 $\pm 6 . I$; TNF- $\alpha$ : I5 \pm 14.I; HBIOI: $16.1 \pm 9.4$, untreated $I \pm 0.4$. $n=4$, Mann-Whitney test: $P>0.05$ ). (C) While TNF- $\alpha$ treatment did cause a moderate, nonsignificant increase in $A B I N I$

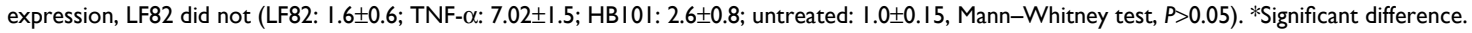

Abbreviations: $\mathrm{CD}$, Crohn disease; TNF- $\alpha$, tumor necrosis factor- $\alpha$; TI, terminal ileum. 
A

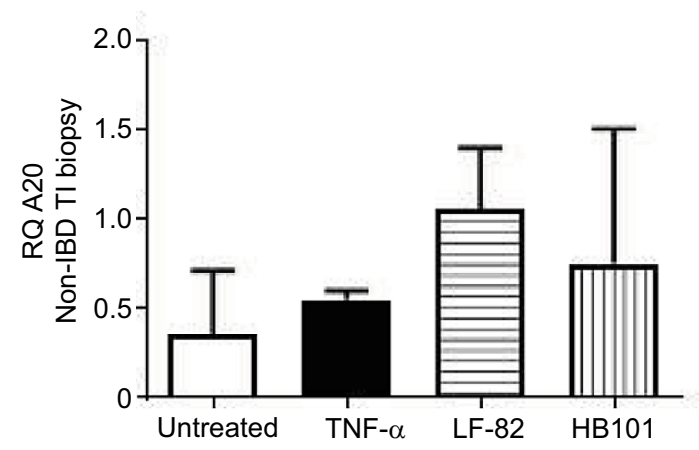

C

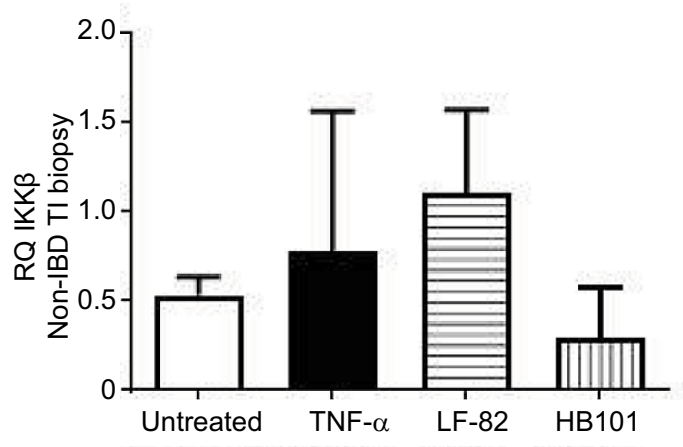

B

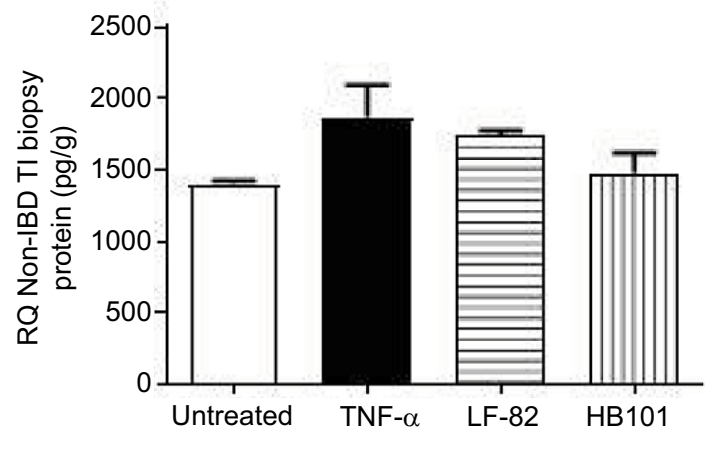

D

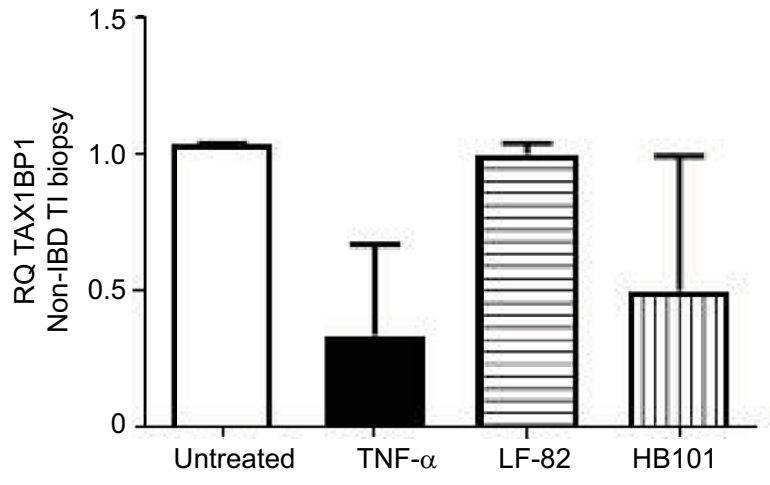

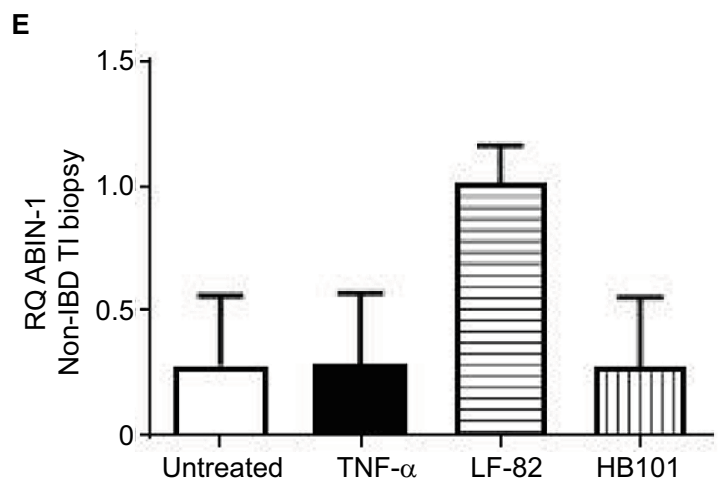

Figure S4 LF82 infection or TNF- $\alpha$ treatment of TI biopsies of non-IBD patients did not alter gene expression or A20 protein levels.

Notes: (A) A20 expression in TI biopsies after treatment (LF82: I.05 \pm 0.3 ; TNF- $\alpha$ : $0.55 \pm 0.05$; HBI 01 : $0.75 \pm 0.7$; untreated: $0.35 \pm 0.3$ ). (B) A20 protein levels in TI biopsies

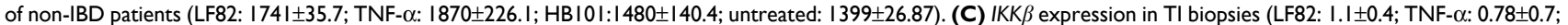
HBI0I: $0.28 \pm 0.2$; untreated: $0.53 \pm 0.10$ ). (D) TAXIBPI expression in TI samples (LF82: I.00I \pm 0.04 ; TNF- $\alpha: 0.33 \pm 0.3$; HBI0I: $0.5 \pm 0.4$; untreated: I.036 \pm 0.005 ). (E) ABIN-I expression in TI biopsies (LF82: I.0 \pm 0.15 ; TNF- $\alpha$ : 0.28 \pm 0.2 ; HBIOI: 0.27 \pm 0.2 ; untreated: 0.28 \pm 0.2 ).

Abbreviations: IBD, inflammatory bowel diseases; TI, terminal ileum; TNF- $\alpha$, tumor necrosis factor- $\alpha$.

Clinical and Experimental Gastroenterology

\section{Publish your work in this journal}

Clinical and Experimental Gastroenterology is an international, peerreviewed, open access, online journal publishing original research, reports, editorials, reviews and commentaries on all aspects of gastroenterology in the clinic and laboratory. This journal is included on PubMed. The manuscript management system is completely online

\section{Dovepress}

and includes a very quick and fair peer-review system, which is all easy to use. Visit http://www.dovepress.com/testimonials.php to read real quotes from published authors. 